\title{
The role of autophagy in the heart
}

\author{
K Nishida ${ }^{1}$, S Kyoi ${ }^{2}$, O Yamaguchi ${ }^{1}$, J Sadoshima ${ }^{2}$ and K Otsu ${ }^{*, 1}$
}

Autophagy has evolved as a conserving process that uses bulk degradation and recycling of cytoplasmic components, such as long-lived proteins and organelles. In the heart, autophagy is important for the turnover of organelles at low basal levels under normal conditions and it is upregulated in response to stresses such as ischemia/reperfusion and in cardiovascular diseases such as heart failure. Cardiac remodeling involves increased rates of cardiomyocyte cell death and precedes heart failure. The simultaneously occurring multiple features of failing hearts include not only apoptosis and necrosis but also autophagy as well. However, it has been unclear as to whether autophagy is a sign of failed cardiomyocyte repair or is a suicide pathway for failing cardiomyocytes. The functional role of autophagy during ischemia/reperfusion in the heart is complex. It has also been unclear whether autophagy is protective or detrimental in response to ischemia/reperfusion in the heart. In this review, we will summarize the role of autophagy in the heart under both normal conditions and in response to stress.

Cell Death and Differentiation (2009) 16, 31-38; doi:10.1038/cdd.2008.163; published online 14 November 2008

\section{Introduction}

Autophagy has evolved as a conserving process for bulk degradation and recycling of cytoplasmic components, such as long-lived proteins and organelles. In nutrient-deprived cells, autophagy is a cell-survival mechanism. ${ }^{1-3}$ There are three main autophagic pathways: macroautophagy, ${ }^{4,5}$ microautophagy ${ }^{6}$ and chaperon-mediated autophagy. ${ }^{7}$ Macroautophagy is the most prevalent form. Autophagy involves sequestration of cytosolic constituents, including proteins and organelles, in autophagosomes. The autophagosomes fuse with lysosomes to form autolysosomes (Figure 1). Class I phosphoinositide 3-kinase (PI3K), the mammalian target of rapamycin (mTOR) pathway, that acts to inhibit autophagy is the well characterized. Autophagy is controlled by autophagyrelated genes (Atgs), many of which are involved in autophagosome formation. Beclin1 (Atg6) and class III PI3K are needed for the vesicle (called isolation membrane) nucleation step of autophagy. The vesicle elongation process features two conjugation systems that are well-conserved among eukaryotes. One pathway involves the conjugation of Atg12 to Atg5 with the help of Atg7 and Atg10. The second pathway involves the conjugation of phosphatidylethanolamine to Atg8 (microtubule-associated protein 1 light chain 3; LC3) by the sequential action of Atg4, Atg7 and Atg3. ${ }^{1,8}$ The conjugation leads to the conversion of the soluble form of LC3 (LC3-I) to the autophagic vesicle-associated form (LC3-II), which is used as a marker of autophagy.
Autophagy plays the role of a cell survival mechanism. Recent studies have demonstrated a variety of physiological and pathophysiological roles in autophagy such as adaptation to nutrient deprivation, intracellular clearance of protein and organelles, elimination of microorganelles including mitochondria, and maintenance of endoplasmic reticulum (ER). Inactivation of Atg genes can cause cell death during in vivo experiments. Mice deficient in Atg5 express a nearly normal phenotype at birth, but die within 1 day of delivery. ${ }^{9}$ One probable explanation is that neonates face severe nutrient deprivation until lactation is fully established. Atg7-deficient mice also die within 1 day after birth for the same reason as Atg5-deficient mice. ${ }^{10}$ Homozygous beclin1-deficient (beclin $1^{-/}$) mice are embryonic lethal at 7.5-8.5 days of embryogenesis. ${ }^{11}$ Paradoxically, autophagy also appears to modulate cell death through excessive self-digestion and degradation of essential cellular constituents. ${ }^{12,13}$

Autophagy plays an important role in the heart. For example, autophagy is important for the turnover of organelles at low basal levels under normal conditions. ${ }^{2}$ In the heart, the level of autophagy is altered not only in response to stress such as ischemia/reperfusion ${ }^{14,15}$ but also to stress triggered by cardiovascular diseases such as cardiac hypertrophy ${ }^{16}$ and heart failure. ${ }^{17,18}$ Heart failure is preceded by a process termed cardiac remodeling, which encompasses the aggregate of compensatory structural and functional changes in response to stress on the chamber wall. The process involves

\footnotetext{
${ }^{1}$ Department of Cardiovascular Medicine, Osaka University Graduate School of Medicine, Suita, Osaka, Japan and ${ }^{2}$ Department of Cell Biology and Molecular Medicine, Cardiovascular Research Institute, University of Medicine and Dentistry of New Jersey, New Jersey Medical School, Newark, NJ, USA

${ }^{*}$ Corresponding author: K Otsu, Department of Cardiovascular Medicine, Osaka University Graduate School of Medicine, 2-2 Yamadaoka, Suita, Osaka 565-0871, Japan. Tel: + 8166879 3635; Fax: +8166879 3645; E-mail: kotsu@ medone.med.osaka-u.ac.jp

Keywords: autophagy; apoptosis; heart failure; ischemia

Abbreviations: AMPK, AMP-activated protein kinase; Atg, autophagy-related gene; eEF2, eukaryotic elongation factor-2; ER, endoplasmic reticulum; HIF-1 $\alpha$, hypoxiainducible factor-1 $\alpha$; LC3, microtubule-associated protein 1 light chain 3; MPT, mitochondrial membrane permeability transition; mTOR, mammalian target of rapamycin; PI3K, phosphoinositide 3-kinase; polyQ, polyglutamine repeat; ROS, reactive oxygen species; shRNA, short hairpin RNA; TAC, transverse aortic constriction; TCA, tricarboxylic acid

Received 04.7.08; revised 06.10.08; accepted 10.10.08; Edited by G Kroeme; published online 14.11.08
} 


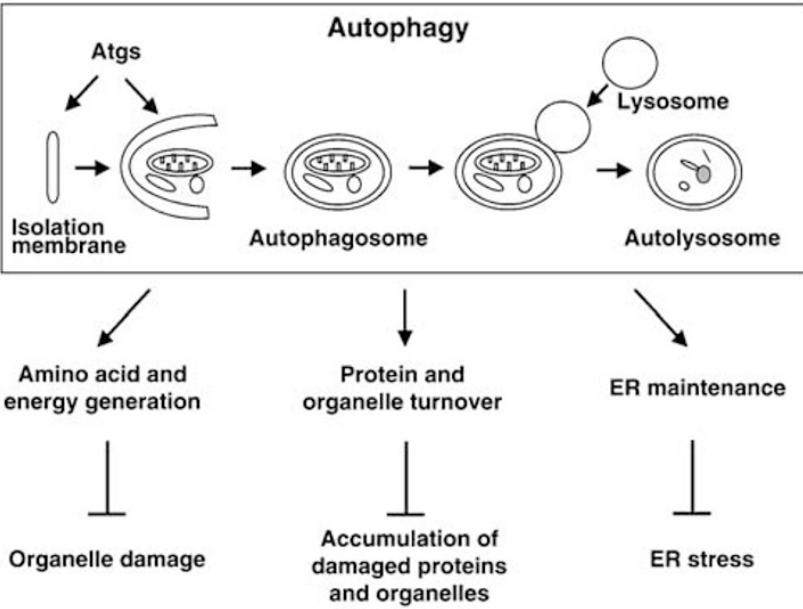

Figure 1 The roles of autophagy. Autophagy involves sequestration of cytosolic constituents, including proteins and organelles, in autophagosomes and degradation in autolysosomes. Autophagy is controlled by Atgs, many of which are involved in autophagosome formation. Autophagy is a cytoprotective mechanism such as recycling amino acids, removing damaged proteins and organelles, and maintaining $\mathrm{ER}$

increased rates of cardiomyocyte cell death. Clinically, heart failure has become the dominant cardiovascular disorder in the Western world despite significant advances in the medical and surgical treatment of heart failure. ${ }^{19-21}$ To prevent progression of cardiac remodeling and heart failure, it is imperative to have a full understanding of the cell death mechanism regarding not only apoptosis and necrosis but also autophagy in cardiomyocytes, and to possess the ability to identify potential therapeutic targets. The multiple features of apoptosis, necrosis and autophagy have been simultaneously observed in failing human hearts. ${ }^{22,23}$ However, it has been unclear whether autophagy is a sign of failed cardiomyocyte repair or is a suicide pathway for failing cardiomyocytes. The functional role of autophagy during ischemia/reperfusion in the heart is complex. It has also been unclear whether autophagy is protective or detrimental in response to ischemia/reperfusion in the heart. In this review, we will summarize the role of autophagy in response to stress in the heart.

\section{Autophagy in the Heart}

Under normal or mildly stressed conditions, autophagy degrades and recycles cytoplasmic components, such as long-lived proteins and organelles, and selectively removes damaged mitochondria as a cytoprotective mechanism. ${ }^{24}$ As damaged mitochondria release pro-apoptotic factors such as cytochrome $c,{ }^{25}$ autophagy can prevent activation of apoptosis. ${ }^{26,27}$ We investigated the role of autophagy in the heart's basal state because cardiomyocytes are mitochondria rich. In earlier reports regarding autophagy in the heart's basal state, it appears to play a protective role in cardiomyocytes. Enhancing autophagy by beclin1 overexpression reduces Bax activation and protects against ischemia/reperfusion injury in cardiac $\mathrm{HL}-1$ cells. ${ }^{14}$ Lysosome-associated membrane
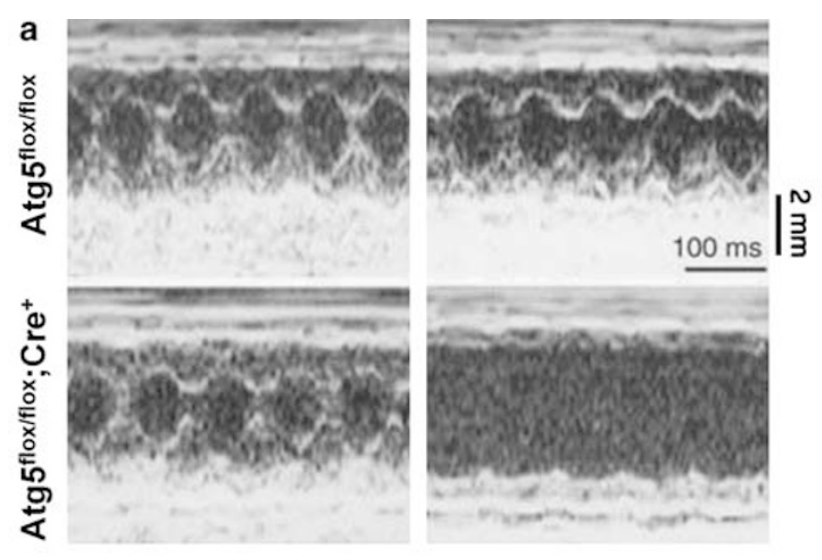

b

Vehicle

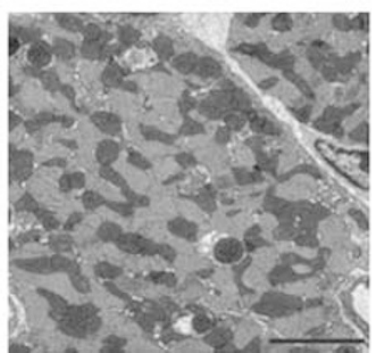

Tamoxifen

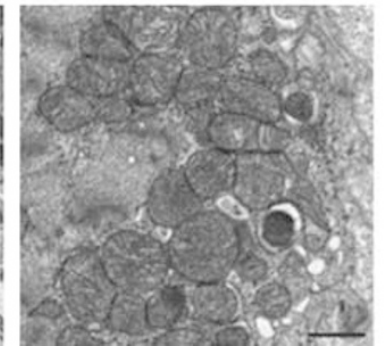

Figure 2 Cardiac dysfunction in tamoxifen-treated $\mathrm{Atg}^{\text {flox/flox}}{ }^{\text {:MerCreMer }}{ }^{+}$ mice. ${ }^{29}$ (a) Echocardiographic analysis. (b) Electron micrographs of tamoxifentreated Atg $5^{\text {floxfllox;}}$,MerCreMer ${ }^{+}$mouse hearts. Scale bars: $5 \mu \mathrm{m}$ in left, $1 \mu \mathrm{m}$ in right

protein 2 (LAMP2)-deficient mice show excessive accumulation of autophagic vacuoles and impaired autophagic degradation of long-lived proteins, resulting in cardiomyopathy. ${ }^{18,28}$ In our examination, autophagy appears to play a protective role in cardiomyocytes. We infected rat neonatal cardiomyocytes with an adenovirus expressing short hairpin RNA (shRNA) targeted to Atg7 (Ad-Atg7-RNAi), encoding the protein Atg7 that is essential for autophagosome formation. Ad-Atg7-RNAi reduces the viable cell number compared with adenovirus expressing nonspecific shRNA. ${ }^{29}$ Furthermore, isolated adult cardiomyocytes from cardiac-specific Atg5deficient hearts are more susceptible than cardiomyocytes isolated from wild-type hearts to isoproterenol. ${ }^{29}$ Temporally controlled cardiac-specific Atg5 deficiency by tamoxifentreated $\mathrm{Atg} 5^{\text {flox/flox }}$;MerCreMer ${ }^{+}$mice $^{30}$ leads to left ventricular dilatation and contractile dysfunction (Figure 2a). ${ }^{29}$ Ultra-structural analyses of Atg5-deficient hearts reveal a disorganized sarcomere structure, misalignment and aggregation of mitochondria, and aberrant concentric membranous structures (Figure 2b). Inactivation of Atg5 causes the accumulation of abnormal proteins and organelles and promotes ER stress and apoptosis. These results indicate that constitutive cardiomyocyte autophagy is required for protein quality control and normal cellular structure and function under the basal state. Accumulation of abnormal proteins and organelles, especially mitochondria, may directly cause cardiac dysfunction. 


\section{Autophagy in Cardiac Hypertrophy}

Cardiac hypertrophy is the consequence of an increase in cardiomyocyte size. As cardiomyocytes have little or no capacity for cellular proliferation, their only means of growth is by hypertrophy. Autophagy has been observed in hypertrophied myocardium. ${ }^{31}$ In earlier reports, autophagy is diminished in response to aortic stenosis ${ }^{16}$ and isoproterenol infusion, ${ }^{32}$ although protein turnover is increased during hypertrophy. Pressure overload develops an increasing rate of myocardial protein synthesis and cardiac hypertrophy. ${ }^{33}$ In our experiments, pressure overload due to transverse aortic constriction (TAC) induces hypertrophy without cardiac dysfunction 1 week after TAC in wild-type mice. ${ }^{34}$ Autophagic activity is suppressed in TAC-induced hypertrophied hearts at the 1 week time point compared with that in sham-operated hearts (Figure 3). ${ }^{29}$ This suggests that autophagic activity is reduced during compensative hypertrophic response. We have also reported that temporally controlled cardiacspecific Atg5 deficiency by tamoxifen-treated Atg $5^{\text {flox/flox }}$ MerCreMer ${ }^{+}$mice leads to cardiac hypertrophy. ${ }^{29}$ Atg7 is also essential for autophagosome formation. Knockdown of Atg7 by Ad-Atg7-RNAi inhibits autophagy in rat neonatal cardiomyocytes and then induces cardiomyocyte hypertrophy with typical characteristics. ${ }^{29}$ Rapamycin, a potent activator of autophagy, prevents cardiac hypertrophy induced by thyroid hormone treatment, $^{35}$ or aortic banding, ${ }^{36}$ and regresses existing cardiac hypertrophy. ${ }^{37}$ These suggest that a decrease in autophagy at the hypertrophied state facilitates cardiac hypertrophic response. However, cardiac hypertrophic response is similar between cardiac-specific Atg5-deficient mice and the control mice after TAC, suggesting that autophagy does not play a role in regulating the cardiomyocyte hypertrophy induced by pressure overload or that its function in the hypertrophic process is compensated by the action of other hypertrophic signaling mechanisms. The role of autophagy in cardiac hypertrophy remains to be elucidated.

\section{Autophagy in Heart Failure}

Autophagy has been observed in failing myocardium caused by dilated cardiomyopathy, ${ }^{17,22,38}$ by valvular disease ${ }^{39}$ and by ischemic heart disease. ${ }^{40-42}$ In patients with terminal heart

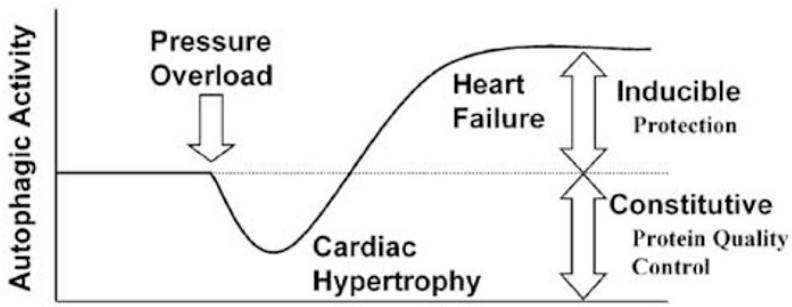

Figure 3 Autophagic activity in heart by pressure overload. Constitutive cardiomyocyte autophagy is a homeostatic mechanism for protein quality control and normal cardiac structure and function under the basal state. During compensative hypertrophic response, autophagic activity is reduced. However, in failing hearts, autophagic activity is upregulated, suggesting that autophagy prevents the accumulation of abnormal proteins or damaged organelles, which can disrupt cardiac function failure, secondary to ischemic cardiomyopathy or dilated cardiomyopathy, cellular degeneration with granular cytoplasmic ubiquitin inclusion is detected in $0.3 \%$ of the cardiomyocytes. $^{38}$ In human failing hearts with idiopathic dilated cardiomyopathy, the prevalence of autophagic, apoptotic and necrotic cells have also been observed. ${ }^{22}$ In animal models, dead and dying cardiomyocytes showing characteristics of autophagy have also been observed. Cardiomyocytes obtained from UM-7.1 hamsters, which is the model of human dilated cardiomyopathy, contain typical autophagic vacuoles, including degraded mitochondria, glycogen granules and myelin-like figures. ${ }^{43}$ In diphtheria toxin receptor transgenic mice, degenerated cardiomyocytes showing characteristics of autophagy have also been observed. ${ }^{44}$ However, the question remains as to whether autophagy is a sign of failed cardiomyocyte repair or is a suicide pathway for the failing cardiomyocytes.

We examined the role of autophagy in cardiac remodeling during sustained pressure overload. In wild-type mice, pressure overload due to TAC induces heart failure 4 weeks after TAC. $^{34}$ Autophagy is upregulated in failing wild-type hearts at the 4-week time point (Figure 3). ${ }^{29}$ Cardiac-specific Atg5 deficiency by Atg $5^{\text {flox/flox;}}$ MLC2v-Cre ${ }^{+}$mice causes cardiac dysfunction and left ventricular dilatation 1 week after TAC. ${ }^{29}$ Polyubiquitinated proteins accumulate, ER stress is increased and apoptosis is promoted in Atg5-deficient hearts. Autophagy can also inhibit $\beta$-adrenergic stress-induced cell death in the heart. Infusion of isoproterenol for 7 days in Atg5 ${ }^{\text {flox/flox }}$;MLC2v-Cre ${ }^{+}$mice leads to left ventricular dilatation and contractile dysfunction compared to that in controls. Furthermore, isolated adult cardiomyocytes from Atg5 ${ }^{\text {flox/flox }}$;MLC2v-Cre ${ }^{+}$mouse hearts were more susceptible to isoproterenol than those from control hearts. These results indicate that upregulation of autophagy in failing hearts is an adaptive response that protects cells either from pressure overload or from isoproterenol stimulation. ${ }^{29}$

\section{Mechanism of Autophagy in Remodeling Hearts}

Accompanying oxidative stress, ER stress and changes in the ubiquitin-proteasomal system are intimately involved in the regulation of autophagy. Under normal or mildly stressed conditions, autophagy degrades and recycles cytoplasmic components, such as long-lived proteins and organelles for protein quality control. Although autophagy can remove damaged organelles such as mitochondria and maintain ER as a cytoprotective mechanism under increasing stress, ${ }^{24,45}$ pro-apoptotic factors are released from the damaged mitochondria, leading to apoptotic cell death. ${ }^{25}$ In particular, in the absence of autophagy, the accumulation of polyubiquitinated proteins may be responsible for increased ER stress, resulting in apoptosis. ${ }^{29}$ However, many of the autophagosomes contain mitochondria in the adult rat myocardium with severe stress such as ischemia/reperfusion, ${ }^{27}$ suggesting that excessive autophagic activity induced by severe stimuli can destroy a large fraction of the cytosol and organelles and release apoptotic-related factors, leading to apoptotic cell death. Under severe pressure overload ${ }^{46}$ and during reperfusion ${ }^{15}$ in beclin $1^{+/}$hearts, autophagy plays a detrimental role. Under extreme stress, the mitochondrial membrane 
permeability transition (MPT), which is defined as the loss of transmembrane potential of the mitochondrial inner membrane, occurs in all damaged mitochondria and the intracellular supply of ATP is exhausted, leading to necrotic cell death. MPT can initiate autophagy of damaged mitochondria in hepatocytes. ${ }^{47}$ Thus, characteristics of autophagy, apoptosis and necrosis can be simultaneously observed in failing hearts. ${ }^{22}$

Several signaling pathways that are induced by common cellular stressors regulate both autophagy and apoptosis. Reactive oxygen species (ROS) not only trigger apoptosis ${ }^{34}$ but are also essential for autophagy and specifically regulate Atg4 activity. ${ }^{48}$ Increases in cytosolic-free $\mathrm{Ca}^{2+}$ concentration not only activate pro-apoptotic signals ${ }^{49}$ but also potently induce autophagy by activating calmodulin-dependent kinase kinase. $^{50}$

Members of the beclin1 and Bcl-2 family serve as a point of cross-talk between the autophagic and apoptotic pathways. Beclin1, which is a mammalian autophagy gene, ${ }^{51}$ was originally identified as a Bcl-2-interacting protein. ${ }^{52}$ Beclin1 directly interacts not only with $\mathrm{Bcl}-2$ but also with other antiapoptotic $\mathrm{Bcl}-2$ family proteins such as $\mathrm{Bcl}-\mathrm{x}_{\mathrm{L}} \cdot{ }^{53,54} \mathrm{Bcl}-2$ inhibits beclin1-dependent autophagy in yeast and mammalian cells. Cardiac Bcl-2 transgenic expression also inhibits autophagy in murine heart cells. ${ }^{53}$ Mutation of the $\mathrm{BH} 3$ domain of beclin1 abolishes the Bcl- $\mathrm{x}_{\mathrm{L}}$-mediated inhibition of autophagy triggered by beclin $1 .{ }^{55}$ Atg 5 also constitutes a point of cross-talk between autophagic and apoptotic pathways. Although Atg5 promotes autophagy as a cytoprotective mechanism, Atg5 also has pro-apoptotic effects. Exposure to pro-apoptotic stimuli activates calpain, which cleaves Atg5. The truncated Atg5 translocates from the cytosol to the mitochondria and associates with the antiapoptotic molecule $\mathrm{Bcl}-\mathrm{x}_{\mathrm{L}}$, provoking apoptotic cell death. ${ }^{56}$ However, the relationship between autophagy and apoptosis is still debated.

\section{Activation of Autophagy by Hypoxia/lschemia and Reperfusion}

Organs and cells highly dependent on a continuous supply of oxygen prepare multiple adaptive responses against hypoxia or ischemia for their survival. These include metabolic adaptation to stimulate glycolysis while limiting oxidative phosphorylation, which helps with reducing oxygen consumption and producing ATP even in a low oxygen environment. Autophagy is among the important mechanisms of hypoxic adaptation and is perhaps one of the last resorts for the salvage of ATP in hypoxic cells and organs. ${ }^{57}$ Amino acids and fatty acids recovered through autophagy are utilized for ATP production as long as the tricarboxylic acid (TCA) cycle is functioning.

Cardiac cells have a remarkable ability to survive hypoxia. For example, although the myocardium under chronic hypoxia exhibits reduced contractility - the condition termed myocardial hibernation - it can show a full recovery with little evidence of cell death when hypoxia is eased. ${ }^{40}$ Hypoxia not only activates a series of cell survival mechanisms but also activates autophagy in the myocardium. ${ }^{40,58}$ An earlier study showed a correlation between the suppression of autophagy and the enhancement of myocardial injury in response to acute myocardial ischemia. ${ }^{15}$ An inverse correlation was found between the occurrence of autophagy and apoptosis in the hibernating myocardium. ${ }^{40}$ Thus, autophagy caused either by transient hypoxia or by chronic mild hypoxia may contribute to the survival of cardiac myocytes. At present, however, whether or not autophagy protects the heart from hypoxia has not been clearly demonstrated in vivo. Addressing this issue is important but may not be easy because attaining significant suppression of autophagy without affecting other cellular functions is a significant challenge. As severe ischemia causes profound depletion of ATP, thereby limiting the occurrence of autophagy as well as the activity of the TCA cycle, there may be a limit to the extent of hypoxia in which myocytes can activate functional autophagy. Because of a very limited availability of collateral vessels in the human heart, occlusion of the coronary artery induces nearly complete ischemia in the risk area. Thus, when complete occlusion of the coronary artery occurs, such as in the case of myocardial infarction in patients, autophagy may take place only transiently after coronary occlusion or at the border zone, where myocardium may obtain low levels of oxygen from the adjacent area through diffusion. These issues may limit conditions where autophagy can be protective against myocardial ischemia under clinical settings.

Although hypoxia alone generally induces modest autophagy, marked accumulation of autophagosome is observed at the reperfusion phase, and prominent upregulation of lysosomal enzymes is observed in the surviving myocardium after myocardial infarction. ${ }^{15}$ These findings are paradoxical in that needs to salvage ATP should have been eased at the time of reperfusion. Importantly, histological evidence shows that the dying cells in the reperfusion area exhibit increases in autophagosomes/autolysosome formation. ${ }^{26}$ In fact, many mechanisms favoring autophagy, such as oxidative stress, mitochondrial damages and ER stress, are activated during reperfusion. The absence of energy crisis and the coexistence of cell death make the property of autophagy during reperfusion distinct from that of hypoxia alone. It is important to note that the question of whether such cell death during the reperfusion phase reflects 'cell death with autophagy' or 'cell death by autophagy' remains to be controversial. ${ }^{59}$

Autophagy during the reperfusion phase may protect cardiac myocytes by eliminating damaged organelles, such as mitochondria and protein aggregates, which would otherwise cause increases in oxidative stress and cellular dysfunction. However, the notion that autophagy can protect the heart during the reperfusion phase has not yet been clearly demonstrated in vivo.

Increasing lines of evidence suggest that autophagy may be involved in non-apoptotic cell death by ischemia/reperfusion. Thus far, this notion has gained more support in the field of brain ischemia. Focal cerebral ischemia (hypoxia) induces autophagy-like delayed cell death of neurons in the peri-infarct zone, termed the ischemic penumbra. ${ }^{60}$ This type of cell death is accompanied by marked accumulation of autophagosomes/autolysosomes and enhanced expression of beclin1, suggesting that overactivation of autophagy may lead to cell death. In brain-specific atg7 KO mice, hypoxia/ischemiainduced cell death of pyramidal neurons was inhibited 
together with autophagy. ${ }^{61}$ This is the first genetic evidence showing that autophagy regulates hypoxia/ischemia-induced death in neurons. Thus, autophagy could be a target of drug treatment to prevent neuronal cell death in stroke patients.

In the heart, both the number of autophagosomes and the size of myocardial infarction were significantly reduced in beclin $1^{+/-}$mice after a period of ischemia followed by reperfusion, a procedure termed ischemia/reperfusion. ${ }^{15}$ Neonatal and adult cardiac myocyte death induced by ischemia/reperfusion was also blocked in the presence of 3-methyladenine, or a knockdown of beclin1, in vitro. ${ }^{62}$ These data suggest that activation of autophagy may be detrimental for the heart during ischemia/reperfusion. How the increased activity of autophagy, such as increased formation of autophagosomes and autophagic flux, leads to increased death of cardiac myocytes remains to be elucidated. Activation of cathepsin causes apoptosis through cleavage/ activation of caspases, ${ }^{63} \mathrm{Bid}^{64}$ and SHP2. ${ }^{65}$ When the permeability of lysosomal membrane is increased, the lysosomal enzymes could spread into the cytoplasm and stimulate massive self-digestion. Chemical inhibitors of cathepsins have been shown to protect the heart from reperfusion injury in experimental animals. ${ }^{66}$ Lysosomal enzymes could be targeted for medical treatment of reperfusion injury.

\section{Mechanism of Autophagy during Ischemia}

Decreases in ATP concentration during myocardial ischemia increase the AMP/ATP ratio and activate AMP-activated protein kinase (AMPK) (Figure 4). ${ }^{15}$ AMPK senses the energy status through four tandem pairs of the cystathionine $\beta$-synthase domain in $\gamma$-subunit and allosterically binds AMP. ${ }^{67}$ AMP binding facilitates AMPK activation by upstream kinases, such as LKB1 and $\mathrm{Ca}^{2+}$ /calmodulin-dependent protein kinase kinase $\beta .^{68}$ In addition, LKB1 can phosphorylate the $\alpha$-subunit of AMPK at Thr172 independently of AMP

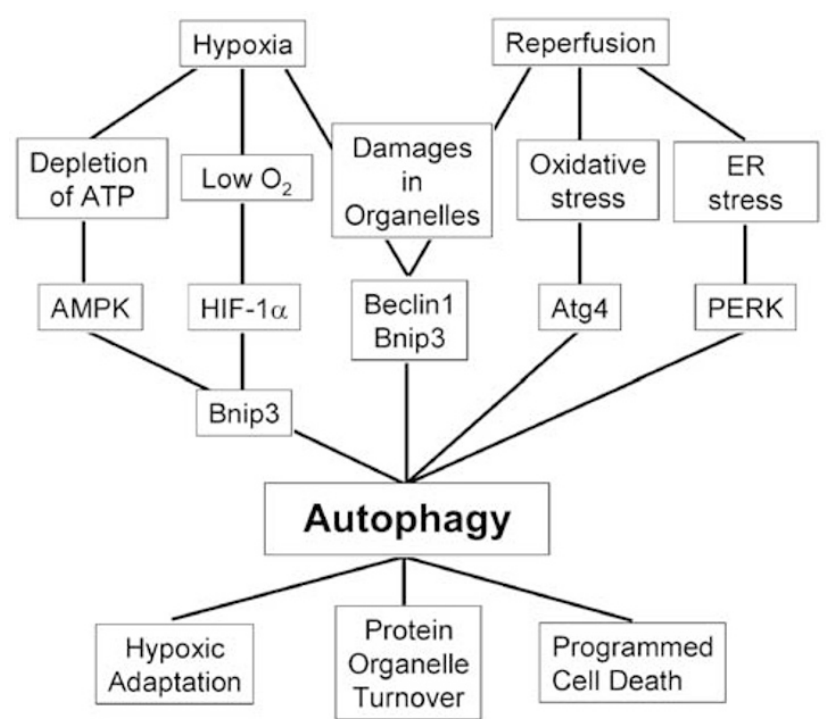

Figure 4 Mechanisms and functions of autophagy during hypoxia/reperfusion in the heart in response to hypoxia. ${ }^{69}$ Earlier, we have shown that AMPK plays an essential role in mediating autophagy in response to myocardial ischemia/hypoxia. ${ }^{15}$ AMPK inhibits mTOR, a negative regulator of autophagy, through phosphorylation of tuberous sclerosis complex 2 (TSC2) and stimulates autophagy possibly through inhibition of mTOR. Activation of AMPK causes inhibition of protein synthesis through phosphorylation of eukaryotic elongation factor-2 (eEF2), rather than inhibition of mTOR, in cardiac myocytes. ${ }^{70}$ eEF2 is phosphorylated by eEF2 kinase, which stimulates autophagy. ${ }^{71}$ Thus, ischemia-induced autophagy may be mediated through the AMPK-eEF2 kinase pathway rather than by the AMPK-induced inhibition of mTOR in the heart.

Hypoxia-inducible factor- $1 \alpha$ (HIF-1 $\alpha$ ) is a transcription factor activated by low oxygen conditions during hypoxia/ ischemia or increased oxidative stress during ischemia/ reperfusion in the heart. Activation of $\mathrm{HIF}-1 \alpha$ reduces reperfusion injury in the heart. ${ }^{72-74}$ Although HIF-1 $\alpha$ has multiple mechanisms to protect the heart, ${ }^{75}$ one of the most significant mechanisms particularly relevant for protecting the heart against ischemia/reperfusion could be its effects on cardiac metabolism. ${ }^{75}$ Activation of endogenous HIF- $1 \alpha$ stimulates the glycolytic pathway ${ }^{76}$ and inhibits the TCA cycle $^{77}$ and fatty acid oxidation, ${ }^{78,79}$ which is beneficial for preserving ATP and reducing $\mathrm{O}_{2}$ consumption during ischemia/reperfusion. ${ }^{80}$ Interestingly, HIF-1 $\alpha$ stimulates mitochondrial autophagy through upregulation of Bnip3 in mouse embryo fibroblasts. ${ }^{81}$ Mitochondrial autophagy activated by the HIF-1 $\alpha$-Bnip3-dependent mechanism causes decreases in the volume of mitochondria, thereby preventing increases in oxidative phosphorylation as well as mitochondrial damage and eventual cell death. ${ }^{81}$ However, as activation of Bnip3 during the reperfusion phase could independently stimulate cell death, whether or not autophagy induced by Bnip3 could be purely protective during hypoxia remains to be demonstrated.

\section{The Mechanism of Autophagy during Reperfusion}

Expression of beclin1 in the heart is dramatically increased in the reperfusion phase in the mouse model of ischemia/ reperfusion. ${ }^{15}$ As heterozygous disruption of beclin1 significantly attenuates autophagy during the reperfusion phase, beclin1 is partially responsible for the upregulation of autophagy. ${ }^{15}$ Strong upregulation of beclin1 by ischemia/ reperfusion is also observed in other tissues, including brain and kidney, and contributes to supra-physiological induction of autophagy. ${ }^{60}$ As many $\mathrm{BH} 3$ domain-containing proteins are highly inducible, common mechanisms, such as $\mathrm{HIF}-1 \alpha$ for induction of Bnip3, may exist for induction of the $\mathrm{BH} 3$ domaincontaining protein family by ischemia/reperfusion. Upregulation of beclin1 after ischemia/reperfusion is suppressed by urocortin through activation of the PI3K/Akt pathway in cardiac myocytes, ${ }^{62}$ which may protect the heart from excessive autophagy.

Production of ROS in mitochondria is dramatically amplified by a mechanism called ROS-induced ROS release when electron transport resumes during reperfusion. ${ }^{82}$ ROS produces damaged proteins and organelles and lipid peroxidation in mitochondria, thereby promoting autophagy. ${ }^{83,84}$ 
As autophagy can target catalase for degradation, which in turn causes accumulation of $\mathrm{H}_{2} \mathrm{O}_{2}$, autophagy and oxidative stress can initiate a positive feedback mechanism and cause autophagic cell death. ${ }^{85}$ ROS may stimulate autophagosome formation through direct oxidative modifications of the autophagic machinery. ${ }^{85}$ For example, $\mathrm{H}_{2} \mathrm{O}_{2}$ oxidizes a cysteine residue of $\mathrm{HsAtg} 4$, inhibits its cysteine protease activity and stimulates starvation-induced autophagy. ${ }^{48}$ ROS also triggers autophagy through mitochondrial damage. For example, BH3-only proteins, such as Bnip3, induce MPT and mitochondrial damage, ${ }^{86}$ which in turn stimulates autophagy. In Saccharomyces cerevisiae, alteration of the mitochondrial F0F1-ATPase complex triggers autophagy. ${ }^{87}$ Some mitochondrial proteins, including Uth1 and Aup1, are involved in autophagic degradation of mitochondria. ${ }^{88}$

Cellular stress under ischemia/reperfusion causes accumulation of misfolded proteins in the ER, the condition collectively called ER stress. Cells initiate a series of compensatory mechanisms termed the unfolded protein response to alleviate ER stress. ${ }^{89}$ Accumulation of misfolded proteins, such as polyglutamine repeat (polyQ)72 aggregates, in the ER induces activation of RNA-dependent protein kinase-like ER kinase (PERK)/eukaryotic initiation factor $2 \alpha$ (elF2 $\alpha$ ), which in turn stimulates autophagy to degrade the polyQ72 aggregates. ${ }^{90}$ Both elF2 $\alpha$ mutation and Atg5 deficiency increase the number of cells showing polyQ72 aggregates. ${ }^{90} \mathrm{~A}$ direct connection may exist between the ER stress and the autophagy machinery. For example, beclin1 is primarily localized at ER and Atg1 has an elevated activity during ER stress-induced autophagy. ${ }^{91}$

\section{Concluding remarks}

Autophagy has evolved as a conserving process that uses bulk degradation and recycling of cytoplasmic components, such as long-lived proteins and organelles. In the heart, autophagy is important for the turnover of organelles at low basal levels under normal conditions and is upregulated in response to stresses such as ischemia/reperfusion and in cardiovascular diseases such as heart failure. According to the analyses of cardiac-specific Atg5-deficient mice, autophagy protects cardiomyocytes from pressure overload or from isoproterenol stimulation. Thus, autophagic features, which have been observed in failing hearts, appear to be a sign of failed cardiomyocyte repair.

The functional role of autophagy during ischemia/reperfusion in the heart is complex. It is possible that the extent of autophagy and its pathophysiological functions depends on the severity and duration of ischemia (hypoxia) and consequent tissue damage during reperfusion in the heart. The level of autophagy may determine whether autophagy is protective or detrimental in response to ischemia/reperfusion in the heart. It is also possible that an upstream signaling mechanism may determine the function of autophagy. For example, autophagy activated by AMPK may be protective, whereas that triggered by dramatic upregulation of beclin1 could be detrimental. However, whether or not functionally distinct forms of autophagy, presumably regulated by distinct signaling mechanisms, really exist is currently unknown. In the clinical setting, physiologically beneficial autophagy should be preserved, whereas excessive autophagy should be eliminated. Elucidation of the role of autophagy in mediating either cell survival or cell death during ischemia (hypoxia)/reperfusion, as well as when and how autophagy is manipulated, would have a significant impact on the treatment of ischemia (hypoxia)-related diseases.

1. Maiuri MC, Zalckvar E, Kimchi A, Kroemer G. Self-eating and self-killing: crosstalk between autophagy and apoptosis. Nat Rev Mol Cell Biol 2007; 8: 741-752.

2. Levine B, Klionsky DJ. Development by self-digestion: molecular mechanisms and biological functions of autophagy. Dev Cell 2004; 6: 463-477.

3. Klionsky DJ, Emr SD. Autophagy as a regulated pathway of cellular degradation. Science 2000; 290: 1717-1721

4. Yang YP, Liang ZQ, Gu ZL, Qin ZH. Molecular mechanism and regulation of autophagy. Acta Pharmacol Sin 2005; 26: 1421-1434.

5. Yorimitsu T, Klionsky DJ. Autophagy: molecular machinery for self-eating. Cell Death Differ 2005; 12 (Suppl. 2): 1542-1552.

6. Kunz JB, Schwarz H, Mayer A. Determination of four sequential stages during microautophagy in vitro. J Biol Chem 2004; 279: 9987-9996.

7. Dice JF. Chaperone-mediated autophagy. Autophagy 2007; 3: 295-299.

8. Ferraro $E$, Cecconi F. Autophagic and apoptotic response to stress signals in mammalian cells. Arch Biochem Biophys 2007; 462: 210-219.

9. Kuma A, Hatano M, Matsui M, Yamamoto A, Nakaya $\mathrm{H}$, Yoshimori T et al. The role of autophagy during the early neonatal starvation period. Nature 2004; 432: 1032-1036.

10. Komatsu M, Waguri S, Ueno T, Iwata J, Murata S, Tanida I et al. Impairment of starvationinduced and constitutive autophagy in Atg7-deficient mice. J Cell Biol 2005; 169: 425-434.

11. Yue Z, Jin S, Yang C, Levine AJ, Heintz N. Beclin 1, an autophagy gene essential for early embryonic development, is a haploinsufficient tumor suppressor. Proc Natl Acad Sci USA 2003; 100: 15077-15082.

12. Levine B, Yuan J. Autophagy in cell death: an innocent convict? J Clin Invest 2005; 115 2679-2688.

13. Shimizu S, Kanaseki T, Mizushima N, Mizuta T, Arakawa-Kobayashi S, Thompson CB et al. Role of $\mathrm{Bcl}-2$ family proteins in a non-apoptotic programmed cell death dependent on autophagy genes. Nat Cell Biol 2004; 6: 1221-1228.

14. Hamacher-Brady A, Brady NR, Gottlieb RA. Enhancing macroautophagy protects against ischemia/reperfusion injury in cardiac myocytes. J Biol Chem 2006; 281: 29776-29787.

15. Matsui $Y$, Takagi $H$, Qu X, Abdellatif M, Sakoda $H$, Asano $T$ et al. Distinct roles of autophagy in the heart during ischemia and reperfusion: roles of AMP-activated protein kinase and Beclin 1 in mediating autophagy. Circ Res 2007; 100: 914-922.

16. Dammrich J, Pfeifer U. Cardiac hypertrophy in rats after supravalvular aortic constriction. II. Inhibition of cellular autophagy in hypertrophying cardiomyocytes. Virchows Arch B Cell Pathol Incl Mol Pathol 1983; 43: 287-307.

17. Shimomura $H$, Terasaki $F$, Hayashi $T$, Kitaura $Y$, Isomura $T$, Suma $H$. Autophagic degeneration as a possible mechanism of myocardial cell death in dilated cardiomyopathy. Jpn Circ J 2001; 65: 965-968.

18. Nishino I, Fu J, Tanji K, Yamada T, Shimojo S, Koori T et al. Primary LAMP-2 deficiency causes X-linked vacuolar cardiomyopathy and myopathy (Danon disease). Nature 2000; 406: $906-910$.

19. Rosamond W, Flegal K, Furie K, Go A, Greenlund K, Haase N et al. Heart disease and stroke statistics - 2008 update: a report from the American Heart Association Statistics Committee and Stroke Statistics Subcommittee. Circulation 2008; 117: e25-e146.

20. Tsutsui H, Tsuchihashi-Makaya M, Kinugawa S, Goto D, Takeshita A. Clinical characteristics and outcome of hospitalized patients with heart failure in Japan. Circ J 2006; 70: 1617-1623.

21. Tsutsui H, Tsuchihashi-Makaya M, Kinugawa S, Goto D, Takeshita A. Characteristics and outcomes of patients with heart failure in general practices and hospitals. Circ J 2007; 71: 449-454.

22. Kostin S, Pool L, Elsasser A, Hein S, Drexler HC, Arnon E et al. Myocytes die by multiple mechanisms in failing human hearts. Circ Res 2003; 92: 715-724.

23. Kostin S. Pathways of myocyte death: implications for development of clinical laboratory biomarkers. Adv Clin Chem 2005; 40: 37-98.

24. Kim I, Rodriguez-Enriquez S, Lemasters JJ. Selective degradation of mitochondria by mitophagy. Arch Biochem Biophys 2007; 462: 245-253.

25. Gustafsson AB, Gottlieb RA. Mechanisms of apoptosis in the heart. J Clin Immunol 2003; 23: $447-459$

26. Decker RS, Wildenthal K. Lysosomal alterations in hypoxic and reoxygenated hearts. I. Ultrastructural and cytochemical changes. Am J Pathol 1980; 98: 425-444.

27. Hamacher-Brady A, Brady NR, Logue SE, Sayen MR, Jinno M, Kirshenbaum LA et al. Response to myocardial ischemia/reperfusion injury involves Bnip3 and autophagy. Cell Death Differ 2007; 14: 146-157.

28. Tanaka Y, Guhde G, Suter A, Eskelinen EL, Hartmann D, Lullmann-Rauch R et al. Accumulation of autophagic vacuoles and cardiomyopathy in LAMP-2-deficient mice. Nature 2000; 406: 902-906. 
29. Nakai A, Yamaguchi O, Takeda T, Higuchi Y, Hikoso S, Taniike $\mathrm{M}$ et al. The role of autophagy in cardiomyocytes in the basal state and in response to hemodynamic stress. Nat Med 2007; 13: 619-624.

30. Sohal DS, Nghiem M, Crackower MA, Witt SA, Kimball TR, Tymitz KM et al. Temporally regulated and tissue-specific gene manipulations in the adult and embryonic heart using a tamoxifen-inducible Cre protein. Circ Res 2001; 89: 20-25.

31. Yamamoto S, Sawada K, Shimomura H, Kawamura K, James TN. On the nature of cell death during remodeling of hypertrophied human myocardium. J Mol Cell Cardiol 2000; 32 161-175.

32. Pfeifer U, Fohr J, Wilhelm W, Dammrich J. Short-term inhibition of cardiac cellular autophagy by isoproterenol. J Mol Cell Cardiol 1987; 19: 1179-1184.

33. Imamura T, McDermott PJ, Kent RL, Nagatsu M, Cooper Gt, Carabello BA. Acute changes in myosin heavy chain synthesis rate in pressure versus volume overload. Circ Res 1994; 75: 418-425.

34. Yamaguchi O, Higuchi Y, Hirotani S, Kashiwase K, Nakayama H, Hikoso S et al. Targeted deletion of apoptosis signal-regulating kinase 1 attenuates left ventricular remodeling. Proc Natl Acad Sci USA 2003; 100: 15883-15888.

35. Kuzman JA, O'Connell TD, Gerdes AM. Rapamycin prevents thyroid hormone-induced cardiac hypertrophy. Endocrinology 2007; 148: 3477-3484.

36. Ha T, Li Y, Gao X, McMullen JR, Shioi T, Izumo S et al. Attenuation of cardiac hypertrophy by inhibiting both mTOR and NFkappaB activation in vivo. Free Radic Biol Med 2005; 39 : 1570-1580.

37. McMullen JR, Sherwood MC, Tarnavski O, Zhang L, Dorfman AL, Shioi T et al. Inhibition of mTOR signaling with rapamycin regresses established cardiac hypertrophy induced by pressure overload. Circulation 2004; 109: 3050-3055.

38. Knaapen MW, Davies MJ, De Bie M, Haven AJ, Martinet W, Kockx MM. Apoptotic versus autophagic cell death in heart failure. Cardiovasc Res 2001; 51: 304-312.

39. Hein S, Arnon E, Kostin S, Schonburg M, Elsasser A, Polyakova V et al. Progression from compensated hypertrophy to failure in the pressure-overloaded human heart: structural deterioration and compensatory mechanisms. Circulation 2003; 107: 984-991.

40. Yan L, Vatner DE, Kim SJ, Ge H, Masurekar M, Massover WH et al. Autophagy in chronically ischemic myocardium. Proc Natl Acad Sci USA 2005; 102: 13807-13812.

41. Elsasser A, Vogt AM, Nef H, Kostin S, Mollmann H, Skwara W et al. Human hibernating myocardium is jeopardized by apoptotic and autophagic cell death. J Am Coll Cardiol 2004; 43: 2191-2199.

42. Depre $\mathrm{C}$, Vatner SF. Cardioprotection in stunned and hibernating myocardium. Heart Fail Rev 2007; 12: 307-317.

43. Miyata S, Takemura G, Kawase Y, Li Y, Okada H, Maruyama R et al. Autophagic cardiomyocyte death in cardiomyopathic hamsters and its prevention by granulocyte colony-stimulating factor. Am J Pathol 2006; 168: 386-397.

44. Akazawa H, Komazaki S, Shimomura H, Terasaki F, Zou Y, Takano H et al. Diphtheria toxin-induced autophagic cardiomyocyte death plays a pathogenic role in mouse model of heart failure. J Biol Chem 2004; 279: 41095-41103.

45. Kitsis RN, Peng CF, Cuervo AM. Eat your heart out. Nat Med 2007; 13: 539-541.

46. Zhu H, Tannous $\mathrm{P}$, Johnstone JL, Kong Y, Shelton JM, Richardson JA et al. Cardiac autophagy is a maladaptive response to hemodynamic stress. J Clin Invest 2007; 117 1782-1793.

47. Elmore SP, Qian T, Grissom SF, Lemasters JJ. The mitochondrial permeability transition initiates autophagy in rat hepatocytes. FASEB J 2001; 15: 2286-2287.

48. Scherz-Shouval R, Shvets E, Fass E, Shorer H, Gil L, Elazar Z. Reactive oxygen species are essential for autophagy and specifically regulate the activity of Atg4. EMBO J 2007; 26: $1749-1760$.

49. Rizzuto R, Pozzan T. Microdomains of intracellular $\mathrm{Ca}^{2+}$ : molecular determinants and functional consequences. Physiol Rev 2006; 86: 369-408.

50. Hoyer-Hansen M, Bastholm L, Szyniarowski P, Campanella M, Szabadkai G, Farkas T et al. Control of macroautophagy by calcium, calmodulin-dependent kinase kinase-beta, and Bcl-2. Mol Cell 2007; 25: 193-205.

51. Liang $\mathrm{XH}$, Jackson S, Seaman M, Brown K, Kempkes B, Hibshoosh $\mathrm{H}$ et al. Induction of autophagy and inhibition of tumorigenesis by beclin 1. Nature 1999; 402 : 672-676.

52. Liang XH, Kleeman LK, Jiang HH, Gordon G, Goldman JE, Berry G et al. Protection against fatal Sindbis virus encephalitis by beclin, a novel Bcl-2-interacting protein. J Virol 1998; 72 8586-8596.

53. Pattingre S, Tassa A, Qu X, Garuti R, Liang XH, Mizushima N et al. Bcl-2 antiapoptotic proteins inhibit Beclin 1-dependent autophagy. Cell 2005; 122: 927-939.

54. Oberstein A, Jeffrey PD, Shi Y. Crystal structure of the Bcl-XL-Beclin 1 peptide complex: Beclin 1 is a novel BH3-only protein. J Biol Chem 2007; 282: 13123-13132.

55. Maiuri MC, Le Toumelin G, Criollo A, Rain JC, Gautier F, Juin P et al. Functional and physical interaction between $\mathrm{Bcl}-\mathrm{X}(\mathrm{L})$ and a $\mathrm{BH}$-like domain in Beclin-1. EMBO J 2007; 26: 2527-2539.

56. Yousefi S, Perozzo R, Schmid I, Ziemiecki A, Schaffner T, Scapozza L et al. Calpainmediated cleavage of Atg5 switches autophagy to apoptosis. Nat Cell Biol 2006; 8 : 1124-1132.

57. Matsui Y, Kyoi S, Takagi H, Hsu CP, Hariharan N, Ago T et al. Molecular mechanisms and physiological significance of autophagy during myocardial ischemia and reperfusion. Autophagy 2008; 4: 409-415.
58. May D, Gilon D, Djonov V, Itin A, Lazarus A, Gordon $O$ et al. Transgenic system for conditional induction and rescue of chronic myocardial hibernation provides insights into genomic programs of hibernation. Proc Natl Acad Sci USA 2008; 105: 282-287.

59. Levine B, Kroemer G. Autophagy in the pathogenesis of disease. Cell 2008; 132: 27-42.

60. Rami A, Langhagen A, Steiger S. Focal cerebral ischemia induces upregulation of Beclin 1 and autophagy-like cell death. Neurobiol Dis 2008; 29: 132-141.

61. Uchiyama Y, Koike M, Shibata M. Autophagic neuron death in neonatal brain ischemia/ hypoxia. Autophagy 2008; 4: 404-408.

62. Valentim L, Laurence KM, Townsend PA, Carroll CJ, Soond S, Scarabelli TM et al. Urocortin inhibits Beclin1-mediated autophagic cell death in cardiac myocytes exposed to ischaemia/reperfusion injury. J Mol Cell Cardiol 2006; 40: 846-852.

63. Ollinger $K$. Inhibition of cathepsin $D$ prevents free-radical-induced apoptosis in rat cardiomyocytes. Arch Biochem Biophys 2000; 373: 346-351.

64. Cirman T, Oresic K, Mazovec GD, Turk V, Reed JC, Myers RM et al. Selective disruption of lysosomes in HeLa cells triggers apoptosis mediated by cleavage of Bid by multiple papainlike lysosomal cathepsins. J Biol Chem 2004; 279: 3578-3587.

65. Rafiq K, Kolpakov MA, Abdelfettah M, Streblow DN, Hassid A, Dell'Italia LJ et al. Role of protein-tyrosine phosphatase SHP2 in focal adhesion kinase down-regulation during neutrophil cathepsin G-induced cardiomyocytes anoikis. J Biol Chem 2006; 281: 19781-19792.

66. Murohara T, Guo JP, Lefer AM. Cardioprotection by a novel recombinant serine protease inhibitor in myocardial ischemia and reperfusion injury. J Pharmacol Exp Ther 1995; 274: 1246-1253.

67. Scott JW, Hawley SA, Green KA, Anis M, Stewart G, Scullion GA et al. CBS domains form energy-sensing modules whose binding of adenosine ligands is disrupted by disease mutations. J Clin Invest 2004; 113: 274-284.

68. Arad M, Seidman CE, Seidman JG. AMP-activated protein kinase in the heart: role during health and disease. Circ Res 2007; 100: 474-488.

69. Baron SJ, Li J, Russell III RR, Neumann D, Miller EJ, Tuerk R et al. Dual mechanisms regulating AMPK kinase action in the ischemic heart. Circ Res 2005; 96: 337-345.

70. Horman S, Beauloye C, Vertommen D, Vanoverschelde JL, Hue L, Rider MH. Myocardial ischemia and increased heart work modulate the phosphorylation state of eukaryotic elongation factor-2. J Biol Chem 2003; 278: 41970-41976.

71. Wu H, Yang JM, Jin S, Zhang H, Hait WN. Elongation factor-2 kinase regulates autophagy in human glioblastoma cells. Cancer Res 2006; 66: 3015-3023.

72. Kido M, Du L, Sullivan CC, Li X, Deutsch R, Jamieson SW et al. Hypoxia-inducible factor 1 alpha reduces infarction and attenuates progression of cardiac dysfunction after myocardial infarction in the mouse. J Am Coll Cardiol 2005; 46: 2116-2124.

73. Natarajan R, Salloum FN, Fisher BJ, Kukreja RC, Fowler III AA. Hypoxia inducible factor-1 activation by prolyl 4-hydroxylase-2 gene silencing attenuates myocardial ischemia reperfusion injury. Circ Res 2006; 98: 133-140.

74. Hofstra L, Liem IH, Dumont EA, Boersma HH, van Heerde WL, Doevendans PA et al. Visualisation of cell death in vivo in patients with acute myocardial infarction. Lancet 2000; 356: 209-212.

75. Shohet RV, Garcia JA. Keeping the engine primed: HIF factors as key regulators of cardiac metabolism and angiogenesis during ischemia. J Mol Med 2007; 85: 1309-1315.

76. Seagroves TN, Ryan HE, Lu H, Wouters BG, Knapp M, Thibault P et al. Transcription factor HIF-1 is a necessary mediator of the Pasteur effect in mammalian cells. Mol Cell Biol 2001; 21: 3436-3444.

77. Kim JW, Tchernyshyov I, Semenza GL, Dang CV. HIF-1-mediated expression of pyruvate dehydrogenase kinase: a metabolic switch required for cellular adaptation to hypoxia. Cell Metab 2006; 3: 177-185.

78. Narravula S, Colgan SP. Hypoxia-inducible factor 1-mediated inhibition of peroxisome proliferator-activated receptor alpha expression during hypoxia. J Immunol 2001; 166: 7543-7548.

79. Belanger AJ, Luo Z, Vincent KA, Akita GY, Cheng SH, Gregory RJ et al. Hypoxia-inducible factor 1 mediates hypoxia-induced cardiomyocyte lipid accumulation by reducing the DNA binding activity of peroxisome proliferator-activated receptor alpha/retinoid $X$ receptor. Biochem Biophys Res Commun 2007; 364: 567-572.

80. Kozarova A, Sliskovic I, Mutus B, Simon ES, Andrews PC, Vacratsis PO. Identification of redox sensitive thiols of protein disulfide isomerase using isotope coded affinity technology and mass spectrometry. J Am Soc Mass Spectrom 2007; 18: 260-269.

81. Zhang H, Bosch-Marce M, Shimoda LA, Tan YS, Baek JH, Wesley JB et al. Mitochondrial autophagy is an HIF-1-dependent adaptive metabolic response to hypoxia. $\mathrm{J} \mathrm{Biol} \mathrm{Chem}$ 2008; 283: 10892-10903.

82. Juhaszova M, Zorov DB, Kim SH, Pepe S, Fu Q, Fishbein KW et al. Glycogen synthase kinase-3beta mediates convergence of protection signaling to inhibit the mitochondrial permeability transition pore. J Clin Invest 2004; 113: 1535-1549.

83. Djavaheri-Mergny M, Amelotti M, Mathieu J, Besancon F, Bauvy C, Souquere S et al. NF-kappaB activation represses tumor necrosis factor-alpha-induced autophagy. J Biol Chem 2006; 281: 30373-30382.

84. Odashima M, Usui S, Takagi H, Hong C, Liu J, Yokota M et al. Inhibition of endogenous Mst1 prevents apoptosis and cardiac dysfunction without affecting cardiac hypertrophy after myocardial infarction. Circ Res 2007; 100: 1344-1352.

85. Scherz-Shouval R, Elazar Z. ROS, mitochondria and the regulation of autophagy. Trends Cell Biol 2007; 17: 422-427. 
86. Webster KA, Graham RM, Thompson JW, Spiga MG, Frazier DP, Wilson A et al. Redox stress and the contributions of BH3-only proteins to infarction. Antioxid Redox Signal 2006; 8: $1667-1676$

87. Nakamura N, Matsuura A, Wada Y, Ohsumi Y. Acidification of vacuoles is required for autophagic degradation in the yeast, Saccharomyces cerevisiae. J Biochem 1997; 121: 338-344.

88. Kissova I, Deffieu M, Manon S, Camougrand N. Uth1p is involved in the autophagic degradation of mitochondria. J Biol Chem 2004; 279: 39068-39074.
89. Ron D. Translational control in the endoplasmic reticulum stress response. J Clin Invest 2002; 110: 1383-1388.

90. Kouroku Y, Fujita E, Tanida I, Ueno T, Isoai A, Kumagai $\mathrm{H}$ et al. ER stress (PERK elF2alpha phosphorylation) mediates the polyglutamine-induced LC3 conversion, an essential step for autophagy formation. Cell Death Differ 2007; 14: 230-239.

91. Yorimitsu T, Nair U, Yang Z, Klionsky DJ. Endoplasmic reticulum stress triggers autophagy. J Biol Chem 2006; 281: 30299-30304. 